\title{
Research on the Innovation of Management Mode in the Construction of Safety Community
}

\author{
Li Zhixin \\ College of Management and \\ Economics \\ Tianjin University, \\ Tianjin, China \\ e-mail: qalizhixin@163.com
}

\author{
$\mathrm{Xu}$ Jingzhen \\ College of Economics \\ Hebei United University \\ Tangshan, China \\ e-mail: xjz0402@yahoo.com.cn
}

\author{
LI Wenli \\ Party committee \\ Tangshan City Party School of the \\ C.P \\ Tangshan, China \\ e-mail: tshdxlwl1966@sina.com
}

\begin{abstract}
The purpose of this study is to explore the thinking of innovation of management mode in the construction of safe community. In this study the community safety management mode is discussed using the theory and method of synergetics. The paper puts forward that in the innovation of the management mode in the construction of safe community, the following aspects should be considered: innovation of the concept of safety management, innovation of safety management strategy, innovation of safety management mode selection basis, innovation of the system of safety management, innovation of safety management carrier, innovation of safety management means.
\end{abstract}

Keywords-community safeyt; safety management mode; innovation

\section{INTRODUCTION}

Safety management system of city community is an open and complicated system. A variety of external or internal factors, including the natural, social, economic, technological and other factors, are likely to have a significant impact on the system. While the various factors in the community security system of the city of mutual interaction each other, at the same time, there are interaction and exchange of substance and energy between the system and the external environment, and in the operation of the system, it obviously reflects the characteristics of the self-organizing, selfadaption and dynamic. According to the synergetics theory, as long as certain conditions provided, a system can change from disordered state to ordered state through selforganization, the self-organization behavior is based on the internal organization, to achieve the goal through various forms of information feedback to control and strengthen the organization behavior of this kind of structure ${ }^{[1]}$. Therefore, in the establishing or choice of the management model of city safety community construction, we should give full consideration to these collaborative characteristics in city community, according to the changes of various factors in community to choose the right mode, and change safety management mode along with the city development and the environment innovation.

\section{INNOVATION OF THE CONCEPT OF SAFETY MANAGEMENT}

Security is one of the most important issues of human society. From the national security in international environment to community safety, enterprise production safety and home safety, people focus on security has not stopped. In the safety community construction, safety is a comprehensive dynamic concept and relevant to quite a wide range of factors. Objectively speaking, security can be understood as the reality that a specific community has not affected by various emergencies or accidents, subjectively speaking, can be understood as the subject of community are not afraid about the threats of emergencies or accidents. In the meantime, security can also be understood as a target, through the comprehensive construction of safe community and the construction of various abilities to prevent threats, the safety construction can reach a certain level.

Under normal circumstances, people's understanding of the security is mainly the traditional security, mainly is as afore said. In the modern economic and social life, the traditional security theory could not fully meet the requirements of the people. With the human-oriented scientific development, comprehensive, harmonious, sustainable development view is widely recognized and accepted by people, people have a new understanding and higher requirements of safety. In the community safety management, there is a need for a comprehensive innovation of safety management mode.

\section{A. The new community safety concept is more rich and wide}

It includes not only the ability or state of the community to combat or the impact of natural disasters, accidents, public health incidents and social security incidents, it should also includes providing people a safe environment, especially a more conducive special space for living and activities of the elderly, the disabled, and the minor.

\section{B. The new community safety concept consider the whole safety management process}

It not only consider the rescue and protection in time after a disaster, but also including the use of modern technology and management methods, to strengthen community security capacity building, nip in the bud, all 
kinds of tangible and intangible risk to eliminate in the bud or fundamentally stop it.

\section{The new community safety concept involves more extensive security subject}

In the new community safety concept, security subject including not only the local government, but also including enterprises, communities and individuals, people at all levels are more concerned about security issues, people focus on security fields include regional security, enterprise security, community security, home security etc.

\section{The new community safety concept involve much mor content in safety community construction}

Community security capacity building includes not only tangible infrastructure, but also to awakening safety culture consciousness of community residents, promote building of safety culture ability.

\section{INNOVATION OF SAFETY MANAGEMENT STRATEGY}

City community is the basic unit of a city, its security situation depends directly on the city public security management strategy. At present, in the public security management research and practice of our country's city, many city haven't put public safety management to a strategic level, thus influence the public safety management of city to a large extent, weakening the basic of community safety construction.

The fifth session of its Party's Sixteen Central Committee of Chinese Communist Party put forward the concept of safe development, tied up safe development with conservation development and clean development, further enrich the connotation of the scientific outlook on development. General Secretary Hu Jintao pointed out in the speech of the thirtieth learning community in the Central Political Bureau that " To involve safe development as an important concept in the overall strategy of China's socialist modernization construction, it is to deepen our understanding of the scientific outlook on development ". Lan Guixing suggested in a paper that "Safe development, is to adhere to the principle of taking security as the foundation, the premise and guarantee in the economic and social development, not at the expense of human life and health, so that the development of the various field, the industry, the production and business units, based on the safety guarantee ability strengthens constantly, production safety situation continued to improve, labor safety and health have basic safeguard, ensure safe production, economic and social development synchronous planning, synchronous deployment, synchronous development, and realize the sustainable development of security." [2]

Innovation of safety management strategy, we should stand at city level, establish the strategic idea, city public security management of strategic goals, strategic focus, strategic steps, strategic guarantee of city public security management, using the overall thought and method of system theory, synergetics theory to consider the safety management of city, to build safe city, safe city proper, provide comprehensive guarantee for the construction of safe community.

\section{INNOVATION OF SAFETY MANAGEMENT MODE SELECTION BASIS}

Safe community management mode choice should be established on the basis of a comprehensive assessment of community safety situation. Through comprehensive evaluation, determine the direction of improvement. From China's current construction of safety community situation, the communities which are named the international safety community and national safety community, safety construction is more standardized in the process of creating a safety community, and through the acceptance of the comprehensive evaluation of the corresponding organization, can they obtain the corresponding title.

But after all, the number of international safety communities and national safety communities only accounts for a very low percentage in our country's communities. For most other domestic communities, because of the limited conditions, temporarily could not meet the corresponding standards, but the choice of safety management mode suitable for the actual situation in the region, should be considered as an important aspect in the construction of safe community.

In the choice of community safety management mode, we should abide by the following ideas: see Figure1.

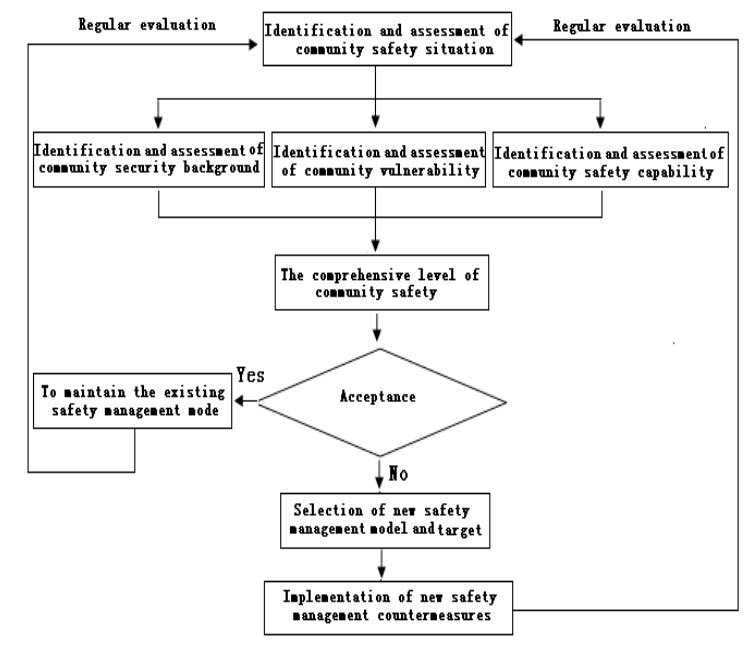

Figure 1. Community safety management mode selection method

\section{INNOVATION OF SAFETY MANAGEMENT SYSTEM}

Establish and improve the safety management system, is the foundation of the innovation of safety management mode. Community safety management system itself is a kind of specification, is a general term for provision of community managers and community members are required to follow in the production, life and standards. Through the establishment of sound safety management system, to regulate, restrain, guide, encourage safety behavior of indifferent units people, set up safety management model system, can enable the 
construction of safety community more security, community security can make more lasting. Generally speaking, security management system content is very wide, can through the establishment of sound safety management organization structure (see Figure 2 ), the establishment of information reporting system, accident and injury record system, accident and injury surveillance system, files and data management system, education and training system, performance evaluation system, safety supervision and management system of public facilities, business units of production safety management system and other safety systems to strengthen the safety management.

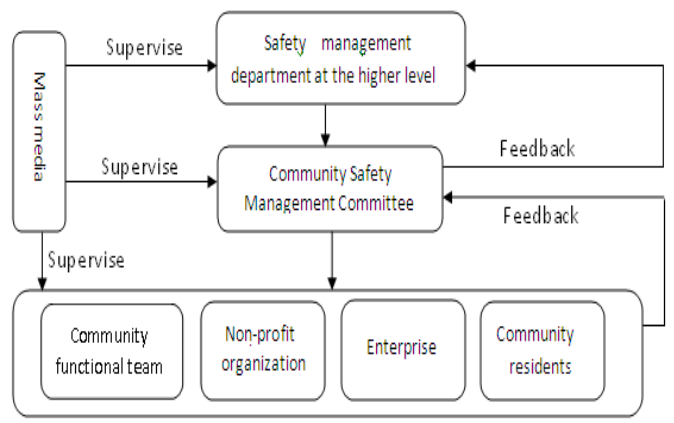

Figure 2. City community safety management organization structure and operation

\section{INNOVATION OF SAFETY MANAGEMENT CARRIER}

In the new situation, accompanied by people pay much more emphasis on safety, community safety construction has gained a good mass base. However, to transfer the masses foundation or potential power into the construction of safety community reality force, we must make use of various carriers, to stimulate the enthusiasm of the masses, to mobilize the construction initiative of the masses, and through proper guidance, standardize people form safety behavior mode. Innovation of safety management carrier mainly includes the follow aspects:

\section{A. Taking the construction of safety community as the carrier}

According to the published data from Chinese occupation safety and Health Association, by August 2011, the international safety community network members have reach a total of 299, the number of Chinese mainland international safety community is 64, by the end of the November 2012, China (mainland) of the national security community has reached $360^{[3]}$. These communities which was awarded the " International Safety Community " or " National safety community " title have achieved outstanding results in the safety construction, but does not represent once these community achieve the initial goal of safety community construction is to finish the task. On the one hand, there is a need to further improvement of the security situation of these communities, on the other hand, more community can improve community safety level and safety skills, improve the safety culture level of community in the process of the construction of safety community. WTO community safety promotion center concluded after a comprehensive analysis of the global safety community network: the successful operation of safety community obviously reduces half of all global 1 trauma, community, region, country should carry out the plan. Thus, any one of the community are expected to create a safety environment, strengthen the security capacity of community, promoting building of safety culture by using the carrier of safety community construction.

\section{B. Taking various competitions as the carrier}

Through various competitions, mobilize the enthusiasm of residents, especially the young people and students to participate in the construction of safety community. Safety knowledge and safety training competition may help extensively publicity emergency knowledge, improving the emergency response capacity of community residents in dealing with emergencies.

\section{Taking the community safety culture as the carrier}

Through safety education, safety behavior training, make the idea of security be established in every community residents.

\section{VII.}

INNOVATION OF SAFETY MANAGEMENT MEANS

The innovation of safety management mode is inseparable from the safety management means. Only through scientific management means, innovation of safety management idea and strategy have the realistic basis, with the guidance of safety management concept and the guarantee of safety management mechanism, to ensure the safety management work to be organized in an orderly manner. Innovation of safety management methods mainly include:

\section{A. Using of electronic information technology.}

With the rapid development of electronic information technology, the use of high-tech information means to achieve the dynamic management of community safety has become a reality. For example, some domestic city have made full use of the effective tool "micro-blog" in traffic safety management, by strengthening the operation management of the micro-blog, make it become the powerful booster in road traffic safety management innovation.

\section{$B$. Fully play the role of grass-roots team}

Difficulties of community safety management are at the grassroots level, focus is also at the grassroots level. Lack of the grass-roots work, community safety would become an empty talk. We should give full play to the grass-roots social management team, such as the grass-roots court and community managers, in resolving contradictions, resolve disputes, reducing crime rate and so on, give full play to the role of civil society organizations, volunteers in a variety of emergency monitoring, to provide timely rescue and relief, to provide assistance for the elderly, the disabled and the minor. 
VIII.

\section{CONCLUSION}

Management mode selection and innovation in the construction of safety community should be based on the factors of safety comprehensive assessment of community and related effects factors on the community, according to the actual situation. Management mode innovation should start from the following aspects: the concept of safety management, safety management strategy, safety manage mode selected basis, the system of safety management, safety management carriers, safety management means etc. Whether management mode choice and innovation is appropriate, should also be comprehensively evaluated on the basis of the effect of the construction of safety community. Therefore, innovation of management mode construction of safety community is a continuous process.

\section{ACKNOWLEDGMENT}

R.B.G. thanks Tangshan City science and Technology Bureau. This paper is one of the results of "Study of the management mode innovation of Tangshan city safety community construction and countermeasures" (Project umber: 12140201B-1 ).

\section{REFERENCES}

[1] Zhang Lirong, Leng Xiangming, "Synergy governance and innovation of public crisis management mode of China- from the perspective of synergetics," in Journal of Huazhong Normal University(Humanities and Social Sciences) vol. 2, 2008, pp.11-19.

[2] Lan Guixing, "The city public security management strategy, " in China Public Security ( Comprehensive Edition ) vol. 10, 2007, pp.86-91.

[3] Chinese occupation safety and Health Association, "Safe Community directory, ” http://www.cosha.org.cn/103275/103465/list.html

[4] Wangbo,"The development of social security management in the developed countries and Its Enlightenment," in Journal of Jilin College of Finance and Taxation, Vol.26, No.3, 2010, pp86-89

[5] Shan Zhigang, "Discussion on safety management model based on behavior," in Journal of Beijing Petroleum Managers Training Institute, Vol. 5, 2010, pp49-52 